\title{
$\mathrm{DCT}$ 기반의 워터마크 재정렬을 이용한 디지털 워터마킹
}

\author{
배 성 호 ${ }^{\dagger}$
}

요 약

워터마킹은 소유권을 주장하기 위하여 워터마크라는 디지털 신호를 영상에 첨가하는 것이다. 본 논문에서는 기존의 DCT를 이용한 디지털 워터마킹 방법을 개선하여 비가시성과 견고성을 동시에 향상시키는 새로운 DCT 기반의 디지털 워터마킹 방법을 제안한다. 제안한 방법에서는 원 DCT 계수의 상대적 중요성이 워터마킹된 DCT 계수에서도 보존되며, 원 DCT 계수의 왜곡을 최소화시키는 워터마크 재정렬 방법을 이용함 으로서 비가시성과 견고성을 향상시킨다. 실험을 통하여 제안한 방법은 기존의 워터마킹 방법보다 바가시성을 약 9 12[dB] 향상시키며, 다양한 공격에 대해 견고성이 월둥히 우수함을 확인하였다.

\section{Digital Watermarking Using Watermark Reordering Based on Discrete Cosine Transform}

\author{
Sung-Ho Bae ${ }^{\dagger}$
}

\begin{abstract}
Watermarking is embedding a digital signal called as watermark into images to claim the ownership. In this paper, a new digital watermarking algorithm based on DCT (Discrete Cosine Transform) which enhances invisibility and robustness is proposed to improve conventional digital watermarking method using DCT. In the proposed method, it is possible to enhance invisibility and robustness using watermark reordering in which the relative significance of original DCT coefficients can be preserved in watermarked DCT coefficients, and the distortions of original DCT coefficients can be minimized. The experimental results show that the proposed method improves invisibility approximately $9 \sim 12$ [dB] and is more robust to various attacks than the conventional method.
\end{abstract}

키워드 : 저작권 보호(Copyright protection), 워터마킹(watermarking), 위터마크 재정렬(watermark reordering), 이산 여현 변환(discrete cosine transform)

1. 서

최근에 네트워크의 발달과 보급을 통해 쉽게 디지털 데이 터의 전송이 가능해짐으로서 디지털 멀티미디어 데이터의 생 산과 사용이 급진전되고 있다. 멀티미디어 데이터의 상업적 가치와 사용 폭이 증가된 반면, 멀티미디어 데이터들이 네트 워크와 인터넷을 통해 쉽게 불법적인 복제나 변조가 가능하 므로 저작권과 보안상의 문제점이 발생된다. 이러한 문제점 을 해결하기 위한 대지털 데이터 정보 보호 방법으로는 기존 의 암호화 알고리즘을 이용하여 주어진 데이터를 암호화하는 방법, 보호 대상 정보에 대하여 접근제어용 방화벽(firewall) 을 구축하는 방법, 그리고 디지털 데이터 내부에 소유권을 보 장할 수 있는 개인 정보를 은닉하여 확인할 수 있는 기술인

† 정 회 원 : 동명정보대학교 멀티미디어공학과 교수

논문접수 : 2002 년 7월 24일, 심사완료 : 2002 년 8월 26 일
디지털 워터마킹 등이 있다[1]. 이중 디지털 워터마킹 방법은 공개키 알고리즘이나 방화벽 등으로 해독된 자료에 대하여 부가적인 정보 보호를 제공하고, 소유권에 대한 법적인 문제 발생 시 해결책을 제시할 수 있어, 최근 디지털 워터마킹 방 법에 대한 연구가 활발히 진행되고 있다[2-4]. 이러한 디지털 워터마킹 기술이 저작권을 효과적으로 보호하기 위해서는 아 래와 같은 중요한 요구사항이 만족되어야 한다[5].

- 비가시성(invisibility) : 위터마크 삽입 여부를 시각적으로 판단할 수 없어야 한다. 시각적으로 판단할 수 없는 워터 마크의 삽입은 원영상의 내용 변화와 의도적인 제거를 막기 위함이다.

- 견고성(robustness) : 외부의 의도적인 변환 및 공격, 잡음 등에 대하여 견고해야 하 며, 여러가지 신호처리, 영상처 리, 기하학적 변환 등에도 견고 해야 한다. 
- 명확성(unambiguity) : 삽입된 워터마크를 추출하여 소 유권자를 명확히 나타내어야 하고, 여러가지 공격이 있을 경우에도 정확도가 많이 낮아지지 않아야 한다.

- 범용성(generality) : 워터마킹 방법은 멀티미디어 데이터 에 범용적으로 적용될 수 있어야 한다. 디지털 멀티미디어 데이터는 음성, 영상, 비디오 등이 흔합된 형태로 존재할 경우가 많기 때문에 동일하게 적용될 수 있는 워터마킹 알고리즘이 생산적일 수 있다.

지금까지 연구되어진 워터마크 방법은 공간 영역예서 영상 의 화소에 워터마크를 직접적으로 삽입하는 방법[2,6-9]과 주파수 변환 영역에서 워터마크를 삽입하는 방법[3-5, 10-15] 으로 나눌 수 있다. 공간 영역에서의 워터마킹 방법은 단순하 고 빠르게 워터마킹을 수행할 수 있는 장점이 있으나 일반적 으로 주파수 영역에서의 워터마킹 방법보다 잡음이나 JPEG 압축 등에 견고성이 낮아지는 단점을 가지고 있다.

주파수 영역에서의 워터마킹 방법은 DCT(Discrete Cosine Transform), FFT(Fast Fourier Transform) 및 DWT(Discrete Wavelet Transform) 둥의 변환 방법을 이용하여 원영 상을 주파수 영역으로 변환한 후, 워터마크를 삽입하는 방법 이다. 기존의 방법들은 원 데이터의 손상을 방지하기 위해 대 부분의 정보를 가지고 있는 저주파 영역에 워터마크를 삽입 하지 않고, 고주파 영역에 워터마크를 삽입하거나 중간 주파 수 대역에 워터마크를 사용하는 방법을 사용하였다[13-15]. 그러나 실제적으로 고주파 영역이나 중간 주파수 대역에 삽 입된 워터마크의 경우 저주파 필터(lowpass filter)나 JPEG 압축 및 잡음에 대해서는 견고성이 약해지는 단점이 있다. 이 러한 문제점을 해결하기 위해 $\operatorname{Cox}$ 등[5]은 DCT 변환을 이용 한 주파수 영역에서의 워터마킹 방법을 제안하였다. 이 방법은 선택된 계수가 저주파 성분이므로 JPEG과 같은 압축 등에는 견고성이 강할 수 있지만 잡음 첨가, 영상처리, 영상 절단 등 과 같은 다양한 공격에 견고하지 못하다.

그러므로 본 논문에서는 $\mathrm{Cox}$ 등이 제안한 $\mathrm{DCT}$ 기반의 워터 마킹 방법을 개선하여 비가시성과 견고성을 동시에 향상시키는 새로운 워터마킹 방법을 제안한다. 본 논문은 2 장에서 기존의 $\mathrm{DCT}$ 기반의 워터마킹 방법과 개선점을 살펴보고, 3장에서 제안한 워터마크 재정렬을 이용한 워터마킹 방법을 설명한다. 4 장에서는 실험을 통하여 제안한 방법과 기존의 방법에 대해 성능을 평가하였으며, 5장에서는 결론 순으로 구성된다.

\section{2. 기존의 DCT 기반의 워터마킹 방법}

$\operatorname{Cox}$ 등은 영상 뿐만아니라 오디오, 비디오 및 멀티미디어 데이터에 적용될 수 있는 $\mathrm{DCT}$ 기반의 워터마킹 방법을 제안 하였다. $\operatorname{Cox}$ 등의 방법에서는 먼저 워터마크를 첨가할 원영상 전체를 $\mathrm{DCT}$ 변환한 다음, $\mathrm{DC}$ 성분을 제외하고 $\mathrm{DCT}$ 계수의 절대치가 큰 $n$ 개의 $\mathrm{DCT}$ 계수 $V=v_{1}, v_{2}, \cdots, v_{n}$ 을 선택 한다. 선택된 DCT 계수에 이진 워터마크보다 견고성이 강인
한 평균이 0 이고 분산이 1 인 정규 분포 $N(0,1)$ 특성의 가 우시안 랜덤 벡터 $X=x_{1}, x_{2}, \cdots, x_{n}$ 을 워터마크로 사용하 고 식 (1)과 같이 삽입하였다.

$$
v_{i}^{\prime}=v_{i}+\alpha v_{i} x_{i}
$$

식 (1)에서 $v_{i}$ 는 선택된 $\mathrm{DCT}$ 계수이며 $v_{i}^{\prime}$ 는 워터마킹된 $\mathrm{DCT}$ 계수이다. 식 (1)은 선택된 DCT 계수의 값이 큰 경우 예는 보다 큰 값이 삽입되고, 적은 경우에는 보다 작은 값이 삽입된다. 이는 일반적으로 큰 값은 작은 값에 비하여 더해지 는 양에 덜 민감하기 때문이다. 식 (1)에서 스케일 인자 $\alpha$ 를 증 가시키면 워터마크로 큰 값이 더해지므로, 워터마크가 삽입 된 영상의 화질은 나빠지지만 외부의 공격에는 더 강인하게 된다. 워터마크 추출 과정에서는 원영상이 필요하며 원영상 과 워터마킹된 영상을 DCT 변환 후, 원영상으로부터 워터마 킹된 영상의 $\mathrm{DCT}$ 계수에서 워터마크가 삽입된 위치를 찾아 내어 식 (1)의 역함수인 식 (2)로 워터마크를 추출할 수 있다.

$$
x_{i}=\frac{v_{i}^{\prime}-v_{i}}{\alpha v_{i}}
$$

$\operatorname{Cox}$ 등의 워터마킹 방법은 시각적으로 중요한 영역인 절대 치가 큰 $\mathrm{DCT}$ 계수에 워터마크를 삽입하여 워터마크의 견고 성을 강하게 하였다. 이는 시각적으로 중요한 영역에 공격을 가할 경우 화질이 심하게 왜곡되므로, 일반적인 외부 공격이 절대치가 작은 $\mathrm{DCT}$ 계수를 공격하는 톡성을 이용한 것이다. $\mathrm{COx}$ 등의 방법은 식 (1)과 같이 선택된 DCT 계수에 일정한 값 $\alpha v_{i} x_{i}$ 를 더하여 워터마크를 삽입하였다. 더해지는 $\alpha v_{i} x_{i}$ 의 절대값이 작을수록 원 $\mathrm{DCT}$ 계수 $v_{i}$ 의 변화가 작게되어 워터 마캉된 영상의 화질은 좋아진다. 그러나 이 방법은 워터마크 $x_{i}$ 가 $v_{i}$ 와 상관없이 곱해져서 $v_{i}$ 에 더해지므로 $v_{i}^{\prime}$ 의 값이 랜덤하게 발생된 $x_{i}$ 의 값에 따라 $v_{i}^{\prime}-v_{i}$ 의 절대값이 커지거 나 작아질 수 있다. 그러므로 비가시성을 높이기 위해 $v_{i}$ 의 변화를 최소로 하는 $x_{i}$ 를 선택하여 $\alpha v_{i} x_{i}$ 의 절대값을 최소 로 하는 방법이 필요하다. 또한 $\operatorname{Cox}$ 등의 방법은 $x_{i}$ 의 부호가 양 $(+)$ 또는 음(-)에 따라서 <표 $1>$ 에서 나타나듯이 $v_{i}^{\prime}$ 의 절 대값이 증가하거나 작아질 수 있다.

〈표 1〉 $v_{i}$ 와 $x_{i}$ 의 부호에 따른 $\left|v_{i}^{\prime}\right|$ 의 변화

\begin{tabular}{|c|c|c|c|}
\hline sign of $v_{i}$ & sign of $x_{i}$ & sign of $v_{i} x_{i}$ & $\left|v_{i}{ }^{\prime}\right|$ \\
\hline \hline+ & + & + & increase \\
\hline+ & - & - & decrease \\
\hline- & + & - & increase \\
\hline- & - & + & decrease \\
\hline
\end{tabular}

이러한 결과는 원 DCT 계수의 절대값의 크기 순서와 워터 마킹된 DCT 계수의 절대값의 크기 순서를 변화시킬 수 있다 $\left(\left|v_{i}\right|\right\rangle\left|v_{j}\right| \Rightarrow\left|v_{i}^{\prime}\right|\left\langle\left|v_{j}^{\prime}\right|\right)$. 즉, 원영상에서 상대적 중요 
성을 가지는 DCT 계수가 워터마킹된 영상에서는 상대적으 로 덜 중요한 DCT 계수로 바뀌는 것이다. 이는 일반적인 외부 공격이 시각적으로 덜 중요한 영역에 집중되므로 원영상에서 상대적으로 중요성을 가지는 DCT 계수가 많은 공격을 받으 며, 상대적으로 보다 덜 중요한 DCT 계수가 작은 공격을 받 게되어 견고성울 약화시키는 결과를 가져온다. 그러므로 원 영상에서 DCT 계수의 상대적 중요성이 워터마킹된 영상에 서도 보존이 되는 방법이 필요하다.

\section{3. 제안한 워터마킹 방법}

본 논문에서는 기존의 $\mathrm{DCT}$ 기반의 디지털 워터마킹 방법 을 개선하여 비가시성과 견고성을 동시에 향상시키는 새로운 디지털 워터마킹 방법을 제안한다. 제안한 방법은 원 DCT 계 수의 상대적 중요성이 워터마킹된 $\mathrm{DCT}$ 계수에서도 보존되 며, 원 DCT 계수의 왜곡을 최소화시키는 워터마크 재정렬 방 법을 이용하여 비가시성과 견고성을 향상시킨다. 제안한 방법 에서는 $\operatorname{Cox}$ 등의 워터마크 생성과 동일한 정규 분포 $N(0,1)$ 톡성을 가진 가우시안 랜덤 벡터 $X$ 를 초기 워터마크로 사용하 였으며, 원영상 전체를 $\mathrm{DCT}$ 변환한 후, $\mathrm{DC}$ 성분을 제외하고 $\mathrm{DCT}$ 계수의 절대치가 큰 $n$ 개의 $\mathrm{DCT}$ 계수 $V=v_{1}, v_{2}, \cdots, v_{n}$ 을 선택한다. 워터마킹된 영상의 비가시성은 식 (1)에서 보듯 이 더해지는 $\alpha v_{i} x_{i}$ 의 절대값이 최소가 될수록 워터마킹된 영 상과 원영상과의 차이가 최소가 되어 워터마킹된 영상의 왜곡 이 작아진다. 그러므로 본 논문에서는 $n$ 개의 워터마크 계수 들 중 식 (3)과 같이 선택된 DCT 계수 $v_{i}$ 의 변화를 최소로 하는 워터마크 계수 $x_{\min }(k)$ 를 찾아내어 워터마크를 삽입하는 방 법을 제안한다.

$$
\begin{aligned}
& x_{\min }(k)=\min \left(\left|v_{i} x_{k}\right|\right), k=0, \cdots, n-1 \\
& v_{i}^{\prime}=v_{i}+\alpha v_{i} x_{\min }(k)
\end{aligned}
$$

그러나 이 방법은 워터마킹된 영상의 비가시성은 향상시킬 수 있으나 다양한 외부 공격에 견고성이 약해지는 단점이 있 다. 그러므로 본 논문에서는 원 DCT 계수의 절대값의 상대 적 크기가 워터마킹된 DCT 계수에서도 보존이 되는 재한 조 건을 만족할 경우, 원 DCT 계수의 왜곡이 최소가 되는 워터 마크 계수를 삽입하여 비가시성과 견고성을 향상시키는 방법 을 제안한다. 제안한 방법에서는 먼저 선택된 DCT 계수에 대해 절대값의 크기가 큰 순으로 식 (4)와 같이 내림차순으로 재정렬 한다.

$$
\left|\widehat{v_{j}}\right|>\left|\widehat{v_{j+1}}\right|, \quad j=0, \cdots, n-2
$$

여기서 $\widehat{v_{0}}$ 는 선택된 $\mathrm{DCT}$ 계수 중 절대값이 가장 큰 계수 를 나타낸다. 제안한 방법에서는 워터마킹된 DCT 계수가 $\left|\widehat{v_{j-1}}\right|>\left|\widehat{v_{j}^{\prime}}\right|$ 을 만족해야 하므로 워터마킹된 $\mathrm{DCT}$ 계수들 에 대한 절대치 비교의 초기값으로 $\widehat{v}_{0}^{\prime}$ 을 설정하였다. 이는 선택된 DCT 계수 중 절대값이 가장 큰 계수의 왜곡을 최소화
함으로서 원 $\mathrm{DCT}$ 계수의 왜곡을 최소화하기 위함이다. 워터 마킹된 $\mathrm{DCT}$ 계수 $\widehat{v}_{0}{ }^{\prime}$ 을 구하기 위해 식 (3)을 이용해 $x_{\min }(k)$ 를 찾아내고, 식 (5)와 같이 재정렬된 워터마크 $\widehat{x}(0)$ 의 생성 과 선택된 워터마크 계수 $x_{k}$ 의 사융됨을 표시한다.

$$
\begin{aligned}
& \widehat{x_{0}}=x_{\min }(k) \\
& x_{k}=\text { used } \\
& \widehat{v_{0}}=\widehat{v_{0}}+\alpha \widehat{v_{0}} \widehat{x_{0}}
\end{aligned}
$$

그리고 다음 $n-1$ 개의 재정렬된 $\mathrm{DCT}$ 계수에 대해 절대값 이 큰 순서로 워터마크를 삽입한다. 워터마크를 삽입하기 위 해 사용되지 않은 워터마크 계수 중 $\left|\widehat{v_{j-1}} \cdot\right|>\left|\widehat{v_{j}^{\prime}}\right|$ 조건을 만족할 경우와 만족하지 않을 경우에 대해 재정렬된 워터마 크 $\widehat{x_{j}}$ 의 생성과 워터마크 삽입을 식 (6)에 나타내었다.

$$
\left.\begin{array}{l}
\widehat{x_{j}}=x_{\min }(k) \\
x_{k}=\text { used } \\
\widehat{v}_{j}^{\prime}=\widehat{v_{j}}+\alpha \widehat{v_{j}} \widehat{x_{j}}
\end{array}\right\}, \text { if }\left|\widehat{v_{j-1}}\right|>\left|\widehat{v}_{j}^{\prime}\right| \text { and } x_{k} \neq \text { used }
$$

식 (6)에서 알 수 있듯이 조건을 만족하지 않는 선택된 $\mathrm{DCT}$ 계수들은 워터마크를 삽입하지 않으며, 재정렬된 워터 마크에 사용되지 않는 워터마크 계수로 표서한다. 제안한 방 법은 초기에 생성된 $n$ 개의 워터마크가 원영상에 따라 재정 렬되며, 워터마크 추출 시 재정렬된 워터마크로부터 워터마크 삽입 여부를 알 수 있다.

제안한 방법은 워터마킹된 DCT 계수의 절대값 크기 순서 가 원 $\mathrm{DCT}$ 계수의 절대값 크기 순서와 동일하고, 원 $\mathrm{DCT}$ 계수의 왜곡을 최소화함으로서 평균 필터(average filter) 등 다양한 공격에 대하여 강인한 견고성을 가진다. 제안된 워터 마킹 알고리즘의 대략적인 과정은 아래와 같으며, (그림 1)과 (그림 2)에서 전체적인 흐름도를 나타내었다.

워터마크 삽입 알고리즘

- 단계 1 : 원영상 전체를 DCT 변환하여 주파수 영역으로 변환한다.

- 단계 $2: \mathrm{DC}$ 성분을 제외한 $\mathrm{DCT}$ 계수 중 절대치가 큰 순 으로 내림차순으로 재정렬하여 워터마킹할 $\mathrm{DCT}$ 계수 $n$ 개를 선택한다.

- 단계 3 : 정렬된 $\mathrm{DCT}$ 계수 중 가장 큰 $\mathrm{DCT}$ 계수의 값이 왜곡이 최소화될 수 있는 워터마크 계수를 찾아 서 워터마크를 삽입한다.

- 단계 4 : 처리되지 않은 $n-1$ 개의 DCT 계수의 워터마킹할 절대값이 이미 워터마킹된 계수의 절대값보다 작 고, 원 DCT 계수의 왜곡이 최소화될 수 있는 워터 마크를 삽입하고 재정렬된 워터마크를 생성한다.

- 단계 5 : 워터마킹된 계수를 원래의 위치로 삽입하고, 역 
DCT 변환하여 워터마크가 삽입된 영상을 생성 한다.

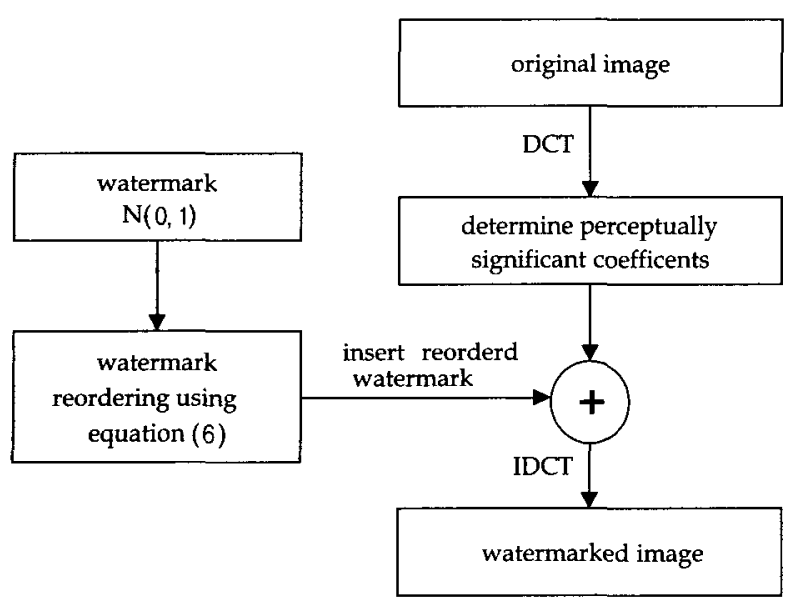

(그림 1) 워터마크 삽입 알고리즘

워터마크 검출 알고리즘

제안한 방법에서는 $\operatorname{Cox}$ 등의 방법과 같이 워터마크 추출 시 원영상을 필요로 한다. 워터마크의 검출은 삽입단계의 역 과정 을 통하여 워터마크를 검출한다.

- 단계 1 : 워터마킹된 영상 또는 공격받은 영상과 원영상 전체를 DCT 변환한다

- 단계 2 : 원영상에서 $\mathrm{DC}$ 성분을 제외한 $\mathrm{DCT}$ 계수 중 절 대치가 큰 순으로 내림차순으로 재정렬하여 워 터마크를 추출할 DCT 계수 $n$ 개를 선택한다.

- 단계 3 : 원영상의 재정렬된 DCT 계수와 재정렬된 워터 마크로부터 워터마크의 삽입 위치를 찾아내고 식 (2)를 이용하여 변형된 영상에서 손상된 워터마 크를 추출한다.

- 단계 4: 추출된 워터마크가 소유권자가 사용한 워터마크 인지 아닌지, 자기 유사도(self similarity)를 이 용한 통계적인 방법으로 판단하고 인증한다.

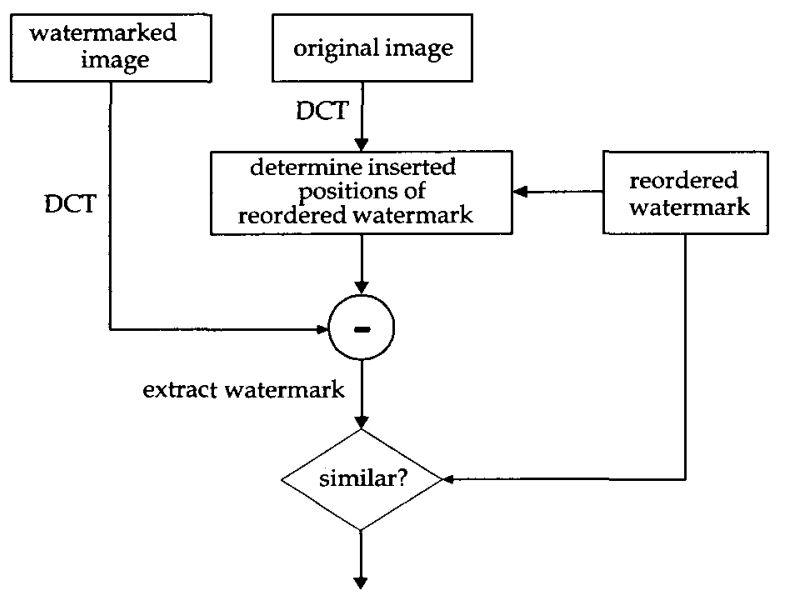

(그림 2) 워터마크 검출 알고리즘
제안한 방법에서는 사용되는 워터마크의 크기가 원영상에 따라 달라지므로 식 (7)과 같이 공격에 대하여 살아남은 워터 마크의 백분율인 자기 유사도를 측정 인자로 사용하였다.

self similarity $\left(x, x^{*}\right)=\frac{\hat{x} \cdot x^{*}}{\sqrt{x^{*} \cdot x^{*}}} / \frac{\hat{x} \cdot \hat{x}}{\sqrt{\hat{x} \cdot \hat{x}}} \times 100[\%]$

여기서 $\hat{x}$ 는 재정렬된 워터마크이고, $x^{*}$ 는 워터마킹된 영상 에서 추출된 워터마크이다.

\section{4. 실험 결과 및 고찰}

제안한 방법은 $256 \times 256$ 크기의 256 해상도로 된 Lena, Cameraman 영상에 대하여 성능을 평가하였다. Cox등의 논문과 동일한 실험 환경을 만들기 위해 스케일인자 $\alpha$ 는 0.1 로 하였 으며, 전체 영상을 $256 \times 256 \mathrm{DCT}$ 변환하여 계수의 절대치가 가장 큰 1000 개를 선택하고 정규 분포 $N(0,1)$ 특성을 가지는 가우시안 랜덤 벡터를 워터마크로 사용하였다. 제안한 방법 은 원영상에 따라 삽입할 워터마크의 수와 워터마크의 시퀀 스(sequence)도 달라진다. 성능 평가의 기준은 워터마크의 비가시도와 견고성에 대하여 성능을 평가하였다. 비가시성에 대한 성능 평가 지수는 워터마킹된 영상과 원영상과의 PSNR 을 사용하고, 견고성에 대한 성능 평가 지수는 식 (7)을 사용 하여 계산된 자기 유사도로 나타내었다. 비가시도에서는 먼 저 시각적으로 워터마크의 삽입 여부를 알 수 없어야 하고, 워터마크 삽입 후에도 원영상에 대한 왜곡이나 변형을 구분 할 수 없어야 한다. 견고성을 확인하기 위해서 워터마킹된 영 상은 영상처리, 압축, 잡음 첨가, 영상 절단 등 다양한 공격에 대하여 견고함을 보여야 한다. 제안한 방법의 성능을 평가하 기 위하여 기존의 $\mathrm{DCT}$ 영역에서의 워터마킹 방법인 $\operatorname{Cox}$ 등 의 방법과 비교하여 성능을 평가하였다.

\section{1 비가시성}

(그림 3)과 (그림 5)는 각각 Lena, Cameraman 원영상이고, (그림 4)와 (그림 6)은 제안한 알고리츰을 사용하여 워터마킹 된 영상을 나타내었다. 그림에서 볼 수 있듯이 시각적으로 워터 마크의 삽입 여부를 구분하기가 어려우며, 화질 저하는 거의 없는 것을 볼 수 있다. Cox등의 제안한 방법은 선택된 DCT 계수의 수를 1000 개로 하였을 때의 방법을 $\operatorname{Cox}$ 등의 방법 I 로 하며, 제안한 방법에서 삽입된 워터마크의 수와 동일하게 워터마크를 생성하였을 때의 방법을 $\operatorname{Cox}$ 등의 방법 $\Pi$ 모 비 교하여 실험하였다. 제안한 방법에서 삽입된 워터마크의 수 가 영상에 따라 적응적으로 구해지므로 Lena 영상에서는 716 개, Cameraman 영상에서는 656개의 워터마크가 삽입되었다. 워터마크 삽입 후, 원영상의 화질 왜곡의 정도를 살펴보기 위해, 원영상과 워터마킹된 영상과의 PSNR을 사용하여 $\mathrm{Cox}$ 뜽의 방법과 제안한 방법의 비교를 <표 2>에 나타내었다. <표 $2>$ 에서 알 수 있듯이 제안한 방법이 원 DCT 계수의 왜곡을 최 소화하여 워터마크를 삽입함으로서 $\operatorname{Cox}$ 등의 방법보다 PSNR 

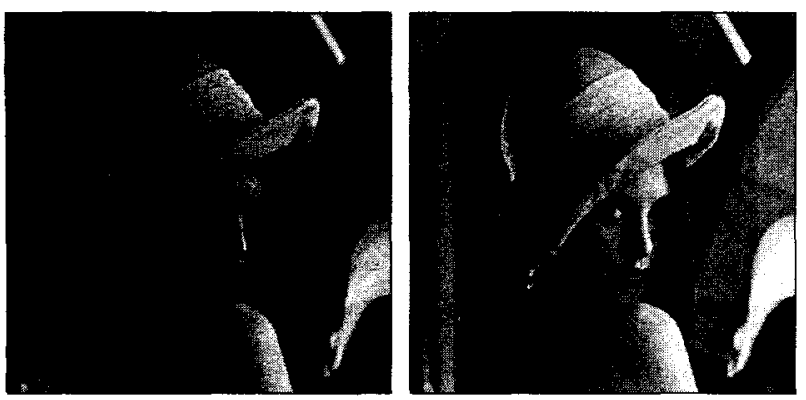

(그림 3) Lena 원영상

(그림 4) 워터마킹된 Lena 영상
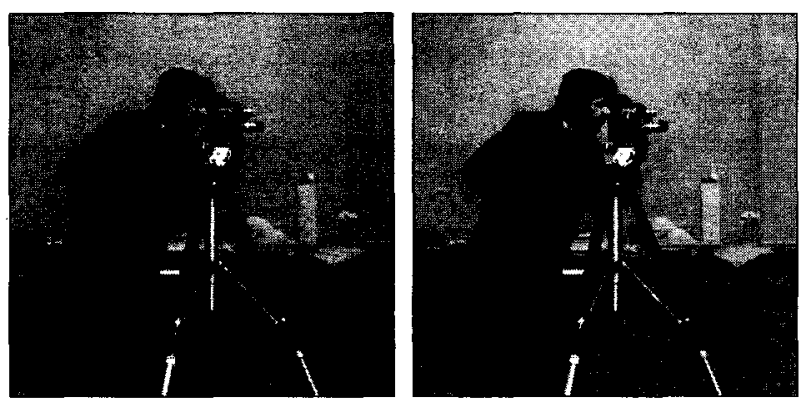

(그림 5) Cameraman 원영상

〈표 2〉 워터마킹된 영상의 PSNR

\begin{tabular}{|c|c|c|c|}
\hline \multirow{2}{*}{ Images } & \multicolumn{3}{|c|}{ PSNR[dB] } \\
\cline { 2 - 4 } & $\begin{array}{c}\text { proposed } \\
\text { method }\end{array}$ & $\begin{array}{c}\text { Cox et al.'s } \\
\text { 1st method }\end{array}$ & $\begin{array}{c}\text { Cox et al.'s } \\
\text { 2nd method }\end{array}$ \\
\hline \hline Lena & 44.40 & 34.92 & 34.63 \\
\hline Cameraman & 43.80 & 31.02 & 32.39 \\
\hline
\end{tabular}

이 약 $10[\mathrm{~dB}]$ 정도로 월등히 개선되는 것을 알 수 있다. 그리 고 $\mathrm{Cox}$ 등의 방법 II가 $\mathrm{Cox}$ 등의 방법 I 보다 삽입된 워터마 크의 수가 작아도 랜덤하게 발생된 워터마크와 원 DCT 계수 를 랜덤하게 대응시켜 워터마크를 삽입함으로서 워터마킹된 영상의 PSNR이 증가 또는 감소됨을 볼 수 있다.

\section{2 견고성}

제안된 워터마킹 알고리즘의 견고성을 평가하기 위하여 워 터마킹된 영상에 대하여 영상처리, 영상압축, 잡음 첨가, 영상 절단의 공격에 대하여 견고성을 확인하였다.

\subsection{1 영상처리}

영상처리에 대한 견고성을 평가하기 위해 워터마킹된 실험 영상에 대하여 공간 영역에서 평균 필터를 수행하였다. <표 $3>$ 은 실험 영상에 대하여 마스크의 크기를 $3 \times 3,5 \times 5,7 \times 7$, $9 \times 9$ 로 다양하게 변형하여 평균 필터를 수행한 후 자기 유사 도를 계산한 결과이다. <표 3>의 결과에서 알 수 있듯이 제 안한 방법이 모든 평균 필터 공격에도 86[\%] 이상의 워터마 크가 살아 있음을 볼 수 있다. 또한 마스크의 크기가 클수록 $\operatorname{Cox}$ 등의 방법은 자기 유사도가 급격히 감소되나, 제안한 방 법은 자기 유사도의 감소가 점점 작게 되어 $\operatorname{Cox}$ 등의 방법보

다 마스크의 크기가 클수록 월등히 강인한 견고성을 가진다.

〈표 3〉 평균 필터의 마스크 크기에 따른 자기 유사도

\begin{tabular}{|c|c|c|r|r|r|c|}
\hline \multirow{3}{*}{$\begin{array}{c}\text { Mask } \\
\text { size }\end{array}$} & \multicolumn{6}{|c|}{ self similarity(\%) } \\
\cline { 2 - 7 } & \multicolumn{2}{|c|}{$\begin{array}{c}\text { Cox et al.'s } \\
\text { proposed method }\end{array}$} & \multicolumn{2}{c|}{$\begin{array}{c}\text { Cox et al.'s } \\
\text { 1st method method }\end{array}$} \\
\cline { 2 - 7 } & Lena & Cameraman & Lena & Cameraman & Lena & Cameraman \\
\hline \hline $3 \times 3$ & 97.16 & 95.03 & 66.50 & 54.50 & 78.10 & 71.90 \\
\hline $5 \times 5$ & 91.69 & 88.58 & 28.74 & 25.48 & 36.29 & 30.92 \\
\hline $7 \times 7$ & 88.45 & 86.44 & 15.01 & 15.35 & 16.67 & 14.25 \\
\hline $9 \times 9$ & 87.23 & 86.53 & 9.12 & 10.49 & 7.75 & 6.77 \\
\hline
\end{tabular}

〈표 4〉JPEG 압축 비율에 따른 자기 유사도

\begin{tabular}{|c|c|c|c|c|c|c|}
\hline \multirow{2}{*}{$\begin{array}{c}\text { Compression } \\
\text { ratio }\end{array}$} & \multicolumn{6}{|c|}{ self similarity(\%) } \\
\cline { 2 - 7 } & \begin{tabular}{c} 
proposed method \\
\cline { 2 - 7 }
\end{tabular} & \multicolumn{2}{|c|}{$\begin{array}{c}\text { Cox et al.'s } \\
\text { 1st method }\end{array}$} & \multicolumn{2}{c|}{$\begin{array}{c}\text { Cox et al.'s } \\
\text { 2nd method }\end{array}$} \\
\hline \hline $10: 1$ & 99.91 & 99.99 & 99.82 & 99.67 & 99.89 & 99.90 \\
\hline $30: 1$ & 99.20 & 99.36 & 98.66 & 98.11 & 99.12 & 99.31 \\
\hline $60: 1$ & 97.20 & 96.97 & 94.10 & 94.45 & 96.51 & 96.95 \\
\hline $90: 1$ & 73.51 & 71.61 & 56.25 & 55.50 & 66.56 & 66.94 \\
\hline $95: 1$ & 48.54 & 46.11 & 32.72 & 30.48 & 35.23 & 30.63 \\
\hline
\end{tabular}

\section{2 .2 영상 압축}

영상 압축에 대한 견고성을 평가하기 위해 워터마킹된 실 혐 영상에 대해 JPEG 압축 비율을 $10,30,60,90$ 으로 다양하 게 변형하여 자기 유사도를 계산한 결과를 <표 4>에 나타내 었다. <표 4>의 결과에서 제안한 방법이 $90: 1$ 의 높은 압축 율에도 $71(\%)$ 이상의 워터마크가 검출되며 고압축율로 영상 을 압축할 경우, $\operatorname{Cox}$ 등의 방법보다 워터마크 검출율이 현저 히 개선됨을 알 수 있다.

\section{2 .3 잡음 첨가}

잡음은 압축과 함께 중요한 공격 중의 하나이다. 네트워크 를 통해서 워터마킹된 영상이 전송될 경우 다양한 잡음이 발 생될 수 있다. 따라서 실험에서는 워터마킹된 실험 영상에 대 해 가장 일반적으로 발생되는 가우시안 잡음을 영상 크기만 큼 발생시켜 전 영역에 잡음을 첨가하였으며, 잡음의 분산을 점점 크게 하여 자기 유사도의 변화를 측정한 결과를 〈표 5> 에 나타내었다. <표 5>의 결과에서 제안한 방법이 $\operatorname{Cox}$ 등의 방법에 비해 자기 유사도 검출율이 개선됨을 알 수 있다.

〈표 5〉가우시안 잡음 첨가에 따른 자기 유사도

\begin{tabular}{|c|c|c|c|c|c|c|}
\hline \multirow{2}{*}{$\begin{array}{c}\text { Noise's } \\
\text { variance }\end{array}$} & \multicolumn{6}{|c|}{ self similarity(\%) } \\
\cline { 2 - 7 } & proposed method & \multicolumn{2}{|c|}{$\begin{array}{c}\text { Cox et al.'s } \\
\text { 1st method }\end{array}$} & \multicolumn{2}{c|}{$\begin{array}{c}\text { Cox et al.'s } \\
\text { 2nd method }\end{array}$} \\
\cline { 2 - 7 } & Lena & Cameraman & Lena & Cameraman & Lena & Cameraman \\
\hline \hline 100 & 89.74 & 89.92 & 79.69 & 84.68 & 86.38 & 88.32 \\
\hline 200 & 82.47 & 82.88 & 68.15 & 74.61 & 77.23 & 79.44 \\
\hline 300 & 77.05 & 77.96 & 60.46 & 67.37 & 70.51 & 72.59 \\
\hline 400 & 72.78 & 74.16 & 54.83 & 61.84 & 65.27 & 67.02 \\
\hline
\end{tabular}




\subsection{4 영상 절단}

영상의 변형이나 왜곡에 있어 무엇보다 많이 가해지는 공격 은 영상을 부분적으로 절단하는 것이다. 실험에서는 워터마킹 된 실험 영상을 $1 / 4$ 크기로 중앙영역을 절단하였다. 제거된 $3 / 4$ 영역은 원영상으로 대치하여 실험한 자기 유사도를 <표 $6>$ 에 나타내었다. <표 6>의 결과에서 원영상의 왜곡을 최소 화하여 워터마크를 삽입함으로서 제안한 방법이 $\operatorname{Cox}$ 등의 방 법보다 약 2 배 정도 성능 향상을 보였다.

〈표 6〉 중앙 영역 절단에 따른 자기 유사도

\begin{tabular}{|c|c|c|c|}
\hline \multirow{2}{*}{ Images } & \multicolumn{3}{|c|}{ self similarity(\%) } \\
\cline { 2 - 4 } & proposed method & $\begin{array}{c}\text { Cox et al.'s } \\
\text { 1st method }\end{array}$ & $\begin{array}{c}\text { Cox et al.'s } \\
\text { 2nd method }\end{array}$ \\
\hline \hline Lena & 82.39 & 42.64 & 41.21 \\
\hline Cameraman & 84.54 & 39.12 & 42.04 \\
\hline
\end{tabular}

\section{5. 결 론}

본 논문에서는 기존의 $\mathrm{DCT}$ 기반의 디지털 워터마킹 방법 을 개선하여 비가시성과 견고성을 동시에 향상시키는 새로운 디지털 워터마킹 방법을 제안하였다. 제안한 방법에서는 워터 마크 재정렬을 통하여, 원 DCT 계수의 상대적 중요성을 워 터마킹된 DCT 계수에서도 보존하였으며, 원 DCT 계수의 예 곡을 최소화시키는 워터마크 계수를 삽입함으로서 워터마킹 된 영상의 비가시성과 견고성을 향상시켰다. 실험을 통하여, 기존의 DCT 영역에서의 워터마킹 방법보다 비가시성과 견 고성에서 월등히 개선됨을 확인하였으며, 특히 평균 필터와 고압축율로 압축을 하였을 경우에도 강인한 견고성을 나타내 었다.

제안된 방법은 워터마크를 확인하기 위해서 원영상이 필요 하다. 향후 연구 과제로는 원영상을 필요로 하지 않는 견고한 워ㄹㅓㅓ마킹 방법에 대한 연구와 제안된 워터마킹 방법을 동영 상에도 확장 적용하는 것이다.

\section{참 고 문 헌}

[1] 원치선, "디지털 영상의 저작권 보호", 정보과학회지, 제 15 권 제12호, pp.22-27, 1997.

[2] A. Nikolaidis and I. Pitas, "Region-based image watermarking," IEEE Trans. Image Processing, Vol.10, No.11, pp. 1726-1740, Nov., 2001.

[3] L. Xie and G. R. Arce, "A class of authentication digital watermarks for secure multimedia communication," IEEE Trans. Image Processing, Vol.10, No.11, pp.1754-1764, Nov., 2001.

[4] V. Solachidis and I. Pitas, "Circulary symmetric watermark embedding in 2-D DFT domain," IEEE Trans. Image Processing, Vol.10, No.11, pp.1741-1753, Nov., 2001.

[5] I. J. Cox, Joe Kilian, F. T. Leighton, and T. Shamoon, "Secure spread spectrum watermarking for multimedia," IEEE Trans. Image Processing, Vol.6, No.12, pp.1673-1687, Dec., 1997.

[6] O. Bruyndonckx, J. J. Quisquater, and B. Macq, "Spatial method for copyright labeling of digital images," in Proc. IEEE Nonlinear Signal and Image Processing, pp.456-459, June, 1995.

[7] P. W. Wong, "A watermark for image integrity and ownership verification," in Pro. IS\&T PIC Conference, May, 1998

[8] W. Bender, D. Gruhl, and N. Morimoto, "Techniques for data hiding," in Proc. SPIE, Vol.2420, p.40, Feb., 1995.

[9] I. Pitas and T. H. Kaskalis, "Signature casting on digital images," in Proc. IEEE Workshop on Nonlinear Signal and Image Processing, 1995.

[10] E. Koch and J. Zhao, "Towards robust and hidden image copyright labeling," Nonlinear Signal Processing Workshop, pp.460-463, 1995

[11] Mitchell D. Swanson, Bin Zhu, and Ahumed. H. Tewfik, "Transparent robust image watermarking," Proc. IEEE International Conference on Image Processing, pp.211-214, 1996.

[12] Deepa Kundur and Dimitrios Hatzinakos, "Digital watermarking using multiresolution wavelet decomposition," Proc. IEEE International Conference on Acoustics, Speech, and Signal Processing, Vol.5, May, 1998.

[13] Chiou-Ting Hsu and Ja-Ling $\mathrm{Wu}$, "Multiresolution watermarking for digital images," IEEE Trans. Circuits Syst. II, Vol.45, No.8, pp.1097-1101, Aug., 1998.

[14] Chiou-Ting Hsu and Ja-Ling $\mathrm{Wu}$, "Hidden digital watermarks in images," IEEE Trans. Image Processing, Vol.8, No.1, pp.58-68, Jan., 1999.

[15] J. Piva, M. Barni, F. Bartolini and V. Cappellini, "DCTbased watermarking restoring to the uncorrupted original image," IEEE Int. Conf. on Image Processing, Vol.1, pp.520523,1997

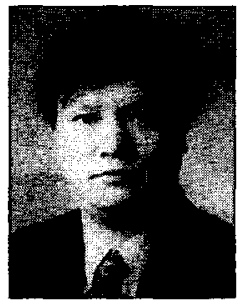

\section{배 성 호}

e-mail : baesh@tmic.tit.ac.kr 1991년 경북대학교 전자공학과(공학사) 1993년 경북대학교 전자공학과(공학석사) 1997년 경북대학교 전자공학과(공학박사) 1998년 1999년 삼성전자 선임연구원 1999년 2001년 동명정보대학교 멀티미디어 공학과 전임강사

2001년 현재 동명정보대학교 멀티미디어공학과 조교수 관심분야 : 정보 보안, 영상 처리, 컴퓨터 비젼, 영상 압축 